\title{
CHIMERA: A BIM+GIS SYSTEM FOR CULTURAL HERITAGE
}

\author{
F. Rechichi ${ }^{1,2, *}$ \\ ${ }^{1}$ Dept. of Architecture, Built environment, and Construction engineering (ABC), Politecnico di Milano, Milano, IT - \\ fabrizio.rechichi@polimi.it \\ ${ }^{2}$ Dept. of Ingegneria e Architettura, Università degli studi di Parma, Parma, IT - fabrizio.rechichi@studenti.unipr.it
}

Commission VI, WG VI/4

KEY WORDS: BIM, GIS, Cultural Heritage, HBIM, Web Information System, Geospatial Data, Chimera

\begin{abstract}
:
In the last years, many researches are conducted on systems for Cultural Heritage, trying to adapt BIM systems to $\mathrm{CH}$ needs; furthermore, the interest around the integration of BIM systems and GIS systems spreads. Chimera, presented in this paper, is the final product of about 8 years of research on this broad topic and has been specifically conceived for the realm of $\mathrm{CH}$. It joins the small group of ready-to work information systems that allow the concurrently use of different integrated data, as 3D models, point clouds but also 2D maps or images. It also presents different functionalities that allow to work at a multiscale approach, including switching from a "single object level", to the a "building level" with a BIM-style system, to a more extensive "environmental level" GIS-style information system and giving the possibility to manage transversal information and to analyse each case from different point of views and at different level of detail.
\end{abstract}

\section{STATE OF ART}

In the last years, many researchers have been working on the integration of data and measurement techniques supporting metric, remote sensing, and monitoring survey requirements for the archaeological, architectural, urban and natural landscape, conservation, restoration and archiving communities.

The main adopted strategy has been trying to adapt existing or experimental BIM systems to the needs of Cultural Heritage (HBIM).

\subsection{CH NEEDS AND HBIM}

Many different projects have been developed to support the needs of each particular case of study: Batawa (Faie et al., 2011), Parma Cathedral (Bruno et al., 2019), Cortijo del Fraile (Carvajal-Ramírez et al., 2019), Town Hall And Lonja Ofalcañiz (Agustín et al., 2019), Milan Cathedral (Achille et al., Springer, 2020), San Marco in Venice (Fassi et al., 2017), Sacro Monte Calvario di Domodossola (Tommasi et al., 2019) and the other Sacri Monti (Achille et al., 2019), Sultan Mehmet Fatih II Mosque (Di Stefano et al., 2019) and many others.

This strategy fails to cover all the needs of all $\mathrm{CH}$ cases, due to the intrinsic BIM limitations, and can accomplish only parts of the requirements or specific situations. This is why so many different systems have been developed and the reason for the currently fragmented scenario.

On the other side, many specialists and committers finally realized the importance and the usefulness to use the modern technologies both as a support for their work and for monitoring and tracking the changes through time, for the preservation and also for the dissemination.

It is clear nowadays how $\mathrm{CH}$ cannot be forced into a system that is developed for the new buildings (BIM) or infrastructures (GIS) and that many attempts to adapt BIM to them (HBIM) partially failed. Thus, it is necessary to use a different approach, integrating BIM and GIS together in a unique system.

\subsection{INTEGRATION OF BIM DATA INTO GIS}

In the last years the interest around the integration of BIM systems and GIS systems spreads not only at a research-level but also big companies, such as ESRI and Autodesk (Autodesk, 2019), started to cooperate to make part of BIM and GIS data interoperable.

The mainly strategy adopted is to use 3D GIS to import the BIM data; examples can be found in Dore et al. (2012), Barazzetti et al. (2017), Matrone et al. (2019), Amirebrahimi et al. (2016), Baik et al. (2015), Arroyo Ohori et al. (2018), Gilbert et al. (2018), Ma et al. (2017), Liu et al. (2017), Arroyo Ohori et a. (2017), Del Curto et al. (2019), D'Andrea et al. (2019).

Many projects are based on CityGML (CityGML, 2020), an open data model and XML-based format for the storage and exchange of virtual 3D city models.

This strategy has many limitations that arise from the use of GIS: one of the most important concerns the maximum complexity of the 3D models that can be used and their loss of precision when they are displayed using world coordinates.

\section{CHIMERA}

\subsection{Introduction}

Chimera, presented in this paper, is the final product of about 8 years of research on this broad topic and has been specifically thought for the realm of $\mathrm{CH}$ (Fassi et al., 2015; Achille et al., 2020). It is an entirely new system, written from scratch, to overcome the limitation of the previously developed BIM3DSG system (Rechichi et al., 2016) and to accomplish all the specific needs of $\mathrm{CH}$.

Chimera is one of the first ready-to-work web information system that allows the concurrently use of different integrated data, as $3 \mathrm{D}$ models, point clouds but also 2D maps or images. It

\footnotetext{
* Corresponding author
} 
also presents different functionalities that allow to work at a multiscale approach, switching from a "single object level", to the a "building level" with a BIM-style system, to a more extensive "environmental level" GIS-style information system and giving the possibility to manage transversal information and to analyse each case from different point of views and at different level of details.

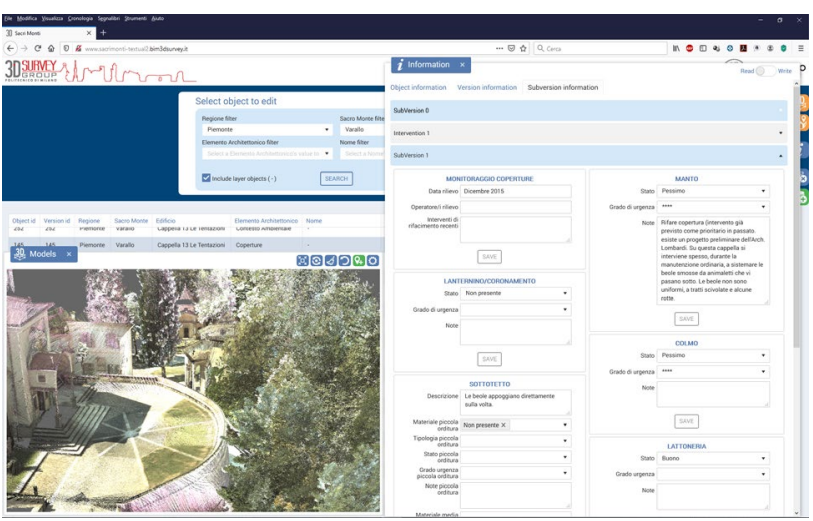

Figure 1 - Example of Chimera workflow; it is shown the textual research fields, a $3 \mathrm{~d}$ point cloud and the information of the last state of an object.

In this sense, Chimera responds to the necessity of managing objects at vastly different representation scales, corresponding to: i) geography, ii) buildings, iii) single and small objects. In many CH's cases of study, there is the necessity to manage concurrently different objects that have i) only a $3 \mathrm{D}$ (or $2,5 \mathrm{D}$ ) model, ii) only a feature on a map, iii) both the previous ones, iv) neither of the previous ones (thus that have only a label); Chimera is specifically designed to support all of them.

This is very important for the Cultural Heritage because in most cases there is the necessity to manage at least objects at two different representation scales and many cases, especially in the archaeologic area, need all three different representation scales. For example, an archaeological area with some buildings remains and many finds.

Chimera can be used concurrently from different kinds of the operator, from different places and from different devices, also in mobility (pc, tablet, smartphone); it has a robust cache system that highly reduces both loading times and the internet traffic and bandwidth needed.

A great attention is dedicated to the UI, to make Chimera very simple to use from everyone, with an attractive, user-friendly interface.

Finally, a standalone OBJ importer is developed to let users to insert the $3 \mathrm{~d}$ models into the system; the importer is developed in C\# and based on ITinnovations Libraries (Rechichi F., 2020).

\subsection{Chimera's global approach}

The idea at the base of Chimera is very different from the various system described in the state of art. Instead to try to adapt a BIM or a GIS system to the all CH's needs or try to import and manage data from each other, Chimera is a completely new system that combines the needed features from BIM and GIS in a unique system.

The core of Chimera is a very complex relational database that includes all data, including all the $3 \mathrm{~d}$ models, the vector $2 \mathrm{~d}$ data, information, images, files; only some raster data, GeoTIFF for the maps and the orthophotos, are stored outside the database, other than eventually external data source for the GIS component.

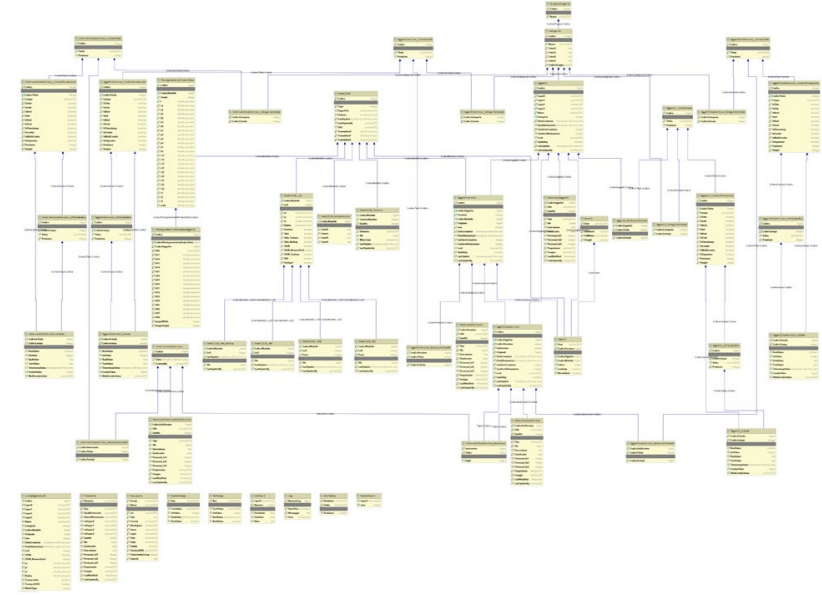

Figure 2 - The database structure of Chimera.

The chosen database is a PostgreSQL (PostgreSQL, 2020), plus the PostGIS extension (PostGIS, 2020) for the geographic data, because its geographical supports and the Open Source license. Chimera offers a web user interface to access to all data and all functionality except for the model's import, that must be done using a standalone application.

The web interface is composed by some component, organized in floating windows, fully integrated and synchronized together:

1. $3 \mathrm{D}$, for visualizing $3 \mathrm{~d}$ mesh and point cloud models.

2. GIS, for visualizing $2 \mathrm{~d}$ maps, raster and vector data.

3. A grid with some research fields, to access to all objects even without the need to loads maps or models; it is named "textual component".

4. Information, to access to all the textual data.

5. Images ${ }^{1}$, for both photos, images and orthophotos.

6. Files ${ }^{1}$, without format restrictions.

Regardless from where the user selects an object in any of the first three component, that object, if loaded, is selected also in the others and all information, images and files are accessible to the user.

Beside these components and related tools, Chimera offers some fundamental functions.

Chimera manages changes and activities through time: i) degradation, ii) monitoring, iii) restoration, iv) preservation... both if the users decide to upload a new model or if a new model is not provided. It is also fundamental that the system can record and show both the previous data and the data for each post-change/activity and the same for models, if provided.

Another important feature is the possibility to manage hotspots onto the 3D models, that allows to georeference objects that have not already a 3D model and to add additional punctual information.

\subsection{D component}

Chimera can use vast and complex non-parametric reality-based 3D models, with high accuracy, high level of details, and with very high-resolution textures, that usually came from the survey (via photogrammetry or laser scans). Furthermore, both meshes and point clouds ${ }^{2}$ are supported, also in the same view.

${ }^{1}$ These features are at the moment available only through the old UI; they are coming soon also for the new UI.

${ }^{2}$ At the moment, it is chosen not to use a dynamic load/unloads of the points, thus all points are always rendered; performance are good until 100 millions of point on a three years old home PC, with a fluid camera movement, and can be higher on a modern PC or on a workstation. 
Meshes can be both textured and untextured; Chimera supports also multi textures (Rechichi et al., 2019) for very highresolution textures.

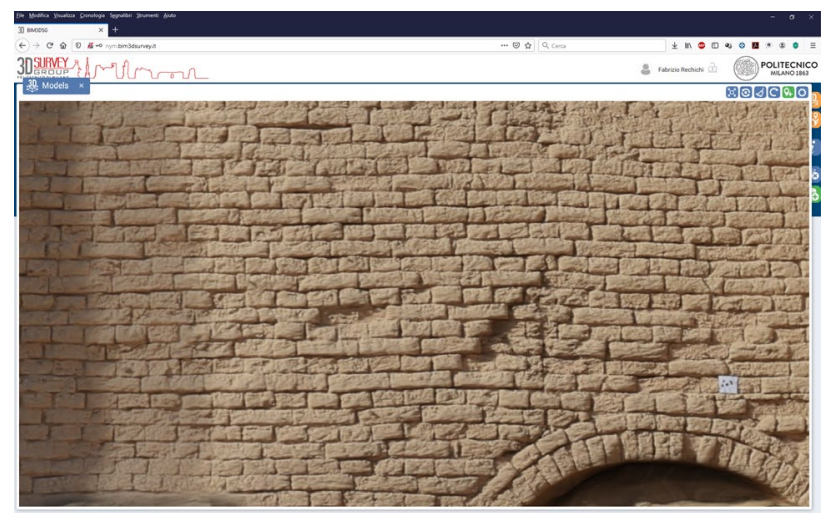

Figure 3 - A detail of a high quality multi textures; Fort of Umm al-Dabadib, shown in Figure 7, with 25 textures of $4.096 \times 4.096$ each, thus 419,43 Gpixel on a model with 6,8 millions of triangles.

Even if it is possible to see the $3 \mathrm{~d}$ models onto GIS maps it is specifically decided to use separate windows for the 2D world GIS and the 3D, because otherwise there will be technological limitation on the precision of the 3D models that can be rendered; if it is needed a 3D map of the terrain of a small area under the $3 \mathrm{~d}$ models can be imported and viewed.

For the same reasons, even if a model is in world coordinates, it is advisable, during the import phase, to setup the parameters for the translation in an appropriate local system for the visualization: Chimera is specifically designed to reconvert on the fly all the data, for example the picked coordinates of a point, in world coordinates, even if the models is displayed in local coordinates.

This feature allows to overcome the technological restrictions, allowing the user to use world coordinates, while the system transparently render objects in local coordinates, thus solving a big problem for $\mathrm{CH}$ and for the integration of GIS and BIM data.

The $3 \mathrm{~d}$ component is written using SceneJS library (xeoLabs, 2020).

\subsection{GIS component}

The GIS component supports satellite images, DEM, highresolution Orthophotos, and base world map, such as OpenStreetMap, with the possibility to manage the GIS features on them.

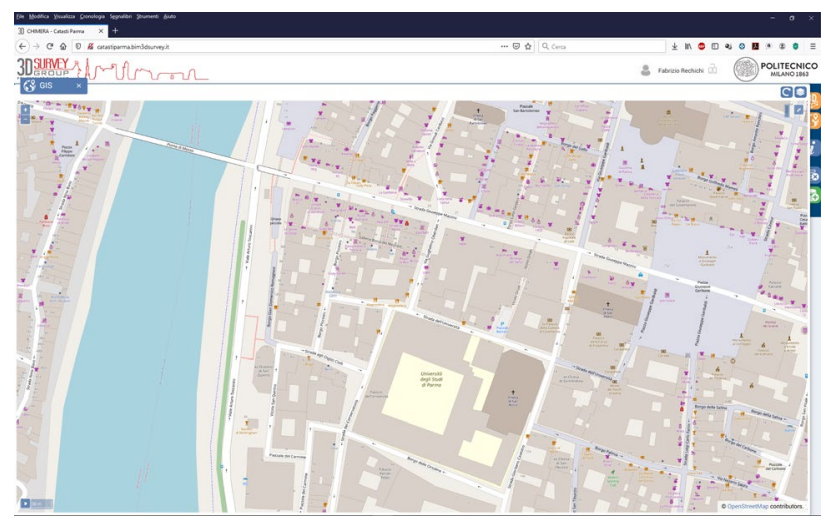

Figure 4 - GIS component working with OpenStreetMap.
The GIS component is written using OpenLayers Library (OpenLayers, 2020) and can load every type of data coming from a WMS Image Source or WMS Vector Source, as that provided by a GeoServer (GeoServer, 2020).

Even if it is not mandatory, Chimera gives the possibility to load the raster data into a GeoServer running on the same server. The Vector sources can be inserted inside its PostGIS database, to perform queries and action directly from Chimera; note that Shapefiles can be easily imported into a PostiGIS database using the common shp2pgsql tool.

When the user clicks on a feature, he can not only identify it, but also automatically query its related PostGIS database to retrieve all information inserted into the PostGIS/Shapefiles, to ensure the data interoperability with already existing GIS systems.

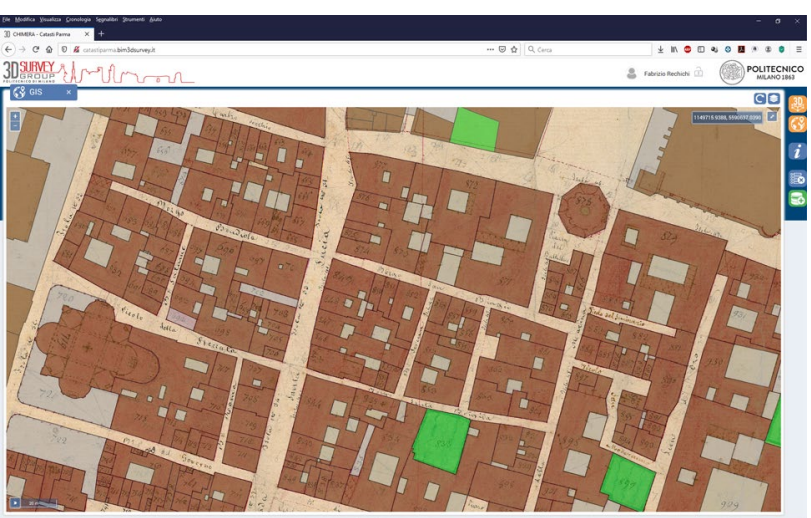

Figure 5 - GIS component working with raster historical maps and vector layers for historical cadaster of Parma.

It is important to remark that many GIS features, one for each vector source, can be concurrently related to each Version of the object; this function is fundamental to analyse the objects from different points of view or at different levels of detail.

The view of all vector sources, including that coming from the PostGIS tables, are rendered inside the GeoServer and not locally, because in this way the user can easily define the styles directly on the GeoServer or from sld files (Open Geospatial Consortium, 2020); Chimera then lets the user to choose all the GeoServer styles provided for each data source.

Moreover, Chimera allows the user to enable/disable each data source and to set the transparency of its layers; it also supports groups for the layers, for fast enabling/disabling groups of them.

\subsection{Objects identification and relationship}

Obviously, a system must define a way to identify the objects and how to correlate them in each component.

Chimera uses a tree hierarchical structure, five levels deep; the leaves can be at each level. This structure can be easily associated to four layers plus name classification, that is a common structure used in $\mathrm{CH}$.

Each leaf is concurrently the start of a one level tree, used for the Version of the object, described in the next chapter.

The decision to adopt a five-level tree was taken after many years of studies and tests with very different study cases, only once it was clear that they were enough to cover both all tested case and most of the possible cases and concurrently force final user to study the best classification and avoid unnecessary fragmentation or confusion.

The levels are also important for a first logical (but can also be spatial and/or temporal) classification and georeferentiation of objects. The name of each layer can be configured in each project; thus, the choice of how to use them is freely 
customizable and each level can be used to different classification purpose.

\subsection{The textual component}

A textual component is added both to allow to add objects that not have neither a $3 \mathrm{~d}$ model or a GIS feature and to have access to all the data, without the need to load and select them in the $3 \mathrm{~d}$ view or GIS view.

The first situation is quite common especially when a new project started, and operators demand to insert data, i.e. from the survey, but the models or the GIS vectors are not ready yet. Furthermore, it is not always possible or advisable to insert all the models or to use the hotspots to georeference objects, but there is the necessity to add information about them.

The second situation is very important i) to use the system in areas with poor internet connection, ii) to fast massive data entry, iii) to help people not get used to use $3 \mathrm{~d}$ and new technologies to start to use the system.

\subsection{Information, images and files components}

All data can be referred to:

- The Object, that is the logical reference to the real object, understood as the core of the object itself, in his immutable part through time.

- The Version (of the object), that represent each state of the object when some event produces a modification of the object and of his model.

- The Model (of the object), that refers to the model, whether it is $3 \mathrm{D}, 2,5 \mathrm{D}$ or a simple hotspot; it is in a direct relationship with the Version and included in its tab.

- Each GIS feature (referred to the object), that refers to a vector (a point, line, polygon, shape, ...) representing the object; it is in a direct relationship with the Version and included in its tab.

- The SubVersion (of the Version of the object), that represent each state of the object when some event produces a modification of the object, but not of its model.

- The Intervention, that refers to each type of event that produces a change in the object; it could be a Version Intervention or a SubVersion Intervention.

It is important to underline that Version and SubVersion are basically the same thing in the reality, but it is necessary to logically separate them in the structure to overcome the need to track the modification even if there is not the possibility or the will of creating a new model for the new situation.

Starting from each of these entities, Chimera allows user to link to each one every type of information and files, therefore offering a highly flexible and fully customizable information system, which can be tailored to cover every possible need.

All data is accessible regardless of objects have i) only a 3D (or $2,5 \mathrm{D}$, or hotspot) model or ii) only a feature on a GIS map, or iii) both of previous ones, or iv) neither of the previous ones (thus that have only a label) and regardless of the user selects the object in the $3 \mathrm{D}$, or in the GIS or from a textual list; furthermore, the system automatically selects and enlightens that object in all three views.

Data can be textual information, images, orthophotos and files of every types.

A flexible information system is at the base of the entire described platform; it can be customized for each project on the fly and at any time, through an admin interface and without changing the code. Furthermore, it can be customized for each different type of object (categories, defined by the admins for each project), adapting the platform to the different cases of study. In details, Chimera provides the capability for admins to define any number of sheets, each of them able to support any number of information fields; then, the admins are able to choose which sheets are visible for each category they define. Each sheet can be related both to the Object or to the Version (and to the Model / GIS features) or to the SubVersion or to the Intervention, so the user can add information that respectively doesn't change through time, that change when an event modify the object's model, when an event that doesn't change the model occurred and that are related to event themselves.

Furthermore, all the additional information included into the PostGIS/Shapefiles of a vector source, are managed inside the Version information tab, as described in 2.4 chapter.

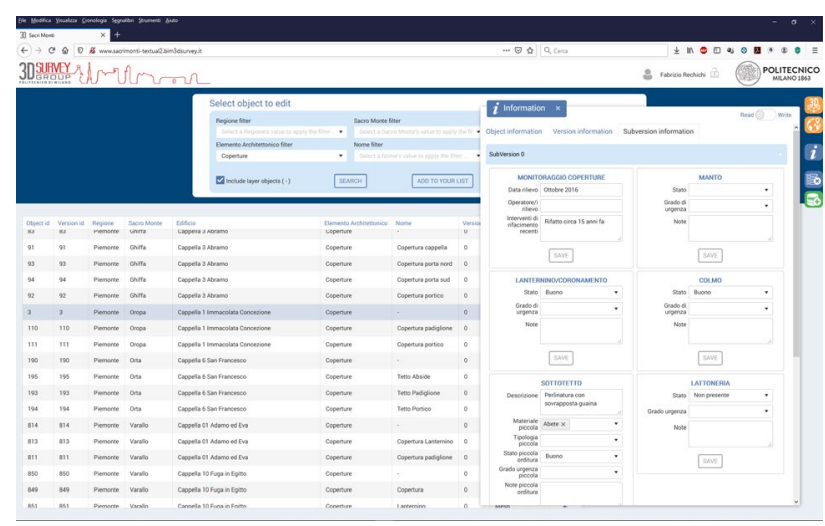

Figure 6 - the information system of Chimera at work; here the textual component is used to select the object, but the information would be the same from the $3 \mathrm{~d} / \mathrm{GIS}$.

Besides textual information, Chimera supports also images and other files of any type. They can be linked both to the Object or to the Version (and to a Model / GIS features) or to the SubVersion or to the Intervention. All the images and the files are stored directly inside the database.

\subsection{Maintenance, monitoring and restoration activities}

Chimera has a complex system to track any change through time, both from natural events, such as degradation, and from maintenance activities, such as restoration.

Chimera calls all these changes "Interventions" and divides them into two different types: i) the changes that cause a modification in the model and for which a new model must be created and ii) the changes that do not modify the model or for which there is no need or will to produce a new model; the former are "Version Intervention" and the latter are "SubVersion Intervention". This separation is fundamental because the system should manage them very differently.

In case of Version Intervention ${ }^{3}$, in order to keep at the same time the history of the objects and their geometrical transformations, the system creates new Version entities referred to the new situation, while keeping the previous ones. Chimera supports any type of relationship between previous and new objects: one to one, one to many, many to one, many to many. It is possible to view both the last model or the previous models or both at once, for comparison intent.

In case of SubVersion Intervention, the model does not change, so the model is the same and we have only a logical tracking of

\footnotetext{
3 The interface for Version Intervention is at the moment available only through the old UI; it is coming soon also for the new UI.
} 
the event plus the related information and files; selecting a Version of the object, the user can access all SubVersion states and all SubVersion Interventions of that specific Version, besides all the related information and files. Every Version can have any number of SubVerision and SubVersion Interventions.

\subsection{Cache system}

For a web system that allows users to load even many GB of models, it is fundamental to have a robust and stable cache system that does not belong to the usual web cache; otherwise, the loading time would be too long in absence of a very powerful fiber connection.

Chimera uses the browser persistent storage (W3C, 2020) to ensure that all $3 \mathrm{~d}$ model, textures and images are cached into its own cache and that are not deleted when the user cleans the common cache.

Thanks to this cache system, after the first load, the loading times are very good because all data are loaded from the local hard disk, if they did not change from the last load.

\subsection{Web Platform and UI}

The choice to base the entire system onto a web platform is important both to the diffusion of the system and the dissemination. The web is nowadays common and familiar to most users; furthermore, it does not require any installation nor any cost for final users.

The user interface is also a key factor to the spread of the system for non-specialist users: having an easy to use, clear, awesome interface is fundamental to help to persuade "old style" users to start to use the system and to change their usually "paper workflow" during their daily activities, that can be more complex than one can imagine.

The Chimera's UI is based on a heavy customized theme of KendoUI (Telerik, 2020). The UI is fully responsive, based on the current size of the web page.

The use of floating windows allows to organize the layout depending on the current activities and the available screen size; the floating windows cannot be moved outside the browser, because it is always a web page and not a desktop application.

\subsection{Performance tests}

\subsubsection{Methodology}

All the tests are based on the huge multi textured model of the Fort of Umm al-Dabadib: the model is composed by 6.803 .780 faces (triangles) and 3.406.360 vertex; the texture is composed by 25 JPEG files of $4.096 \times 4.096$ pixel each, thus having a total texture size of 419,43Mpixel.

Except for the scalability, the tests were performed using a three years old home PC: Intel i7-7700K, with 64GB of system RAM, a Nvidia GTX1070 with 8GB of Video RAM by ASUS and a Samsung 960 PRO SSD.

\subsubsection{Loading Times}

Chimera takes only around 8,03 seconds to draw the scene if the model is in cache; the first time it is loaded, the time instead depends principally from the internet connections: using a $100 \mathrm{Mbit} / \mathrm{s}$ download bandwidth, it takes around 32,74 seconds to download all the data from internet and render the scene. In comparison i) Agisoft takes 25,49s, ii) Geomagic Freeform Plus 45,92s, iii) MeshLab 48,1s and iv) Rinocheros 67,72s, thus Chimera is significantly better than other software in loading times, despite it is working inside a web browser. If the model is not found in cache, but a decent internet connection is available, the loading times remains however very good.

\section{LOADING TIMES \%}

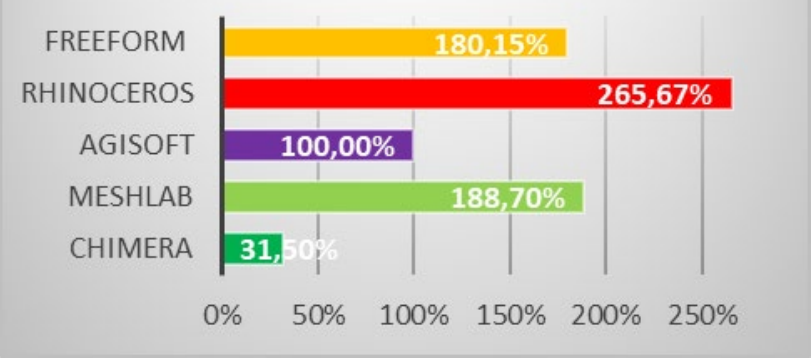

Figure 7 - Loading times in percent, setting Agisoft as $100 \%$; lower is better.

\subsubsection{Fluidity}

In the FPS ${ }^{4}$ test, Chimera frame rate is perfect stable and it is limited by the used monitor locked refresh (60 fps), with no drop; the video card use is only at $30 \%$, thus many resources are available to have higher fps on a better monitor or to draw others object without any slowdown.

In comparison, i) Geomagic Freeform Plus has average fps of only 20,75, ii) Agisoft 8,95, iii) Rhinocheros 8,6 and iv) MeshLab 2,25. Chimera thus allows the user to have the best experience, with a perfect fluidity, without any stuttering or motion sickness, when all other tested software goes from a Geomagic's poor user experience to almost not usable at all for MeshLab.

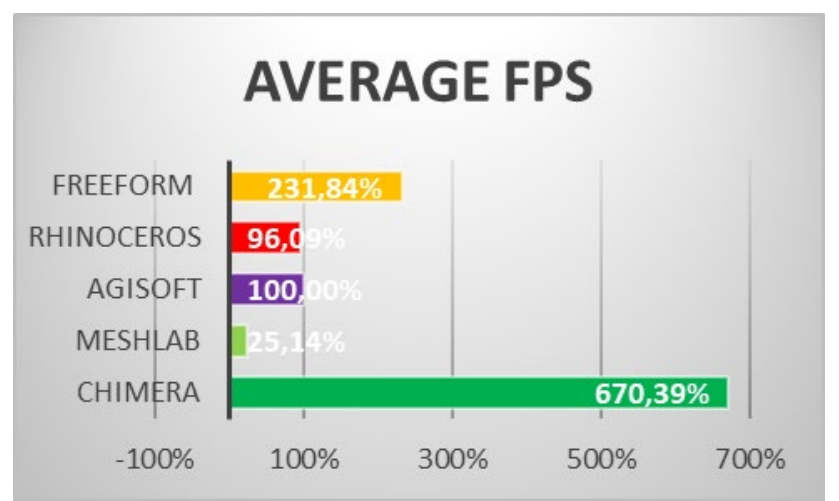

Figure 8 - FPS in percent, settings Agisoft as $100 \%$; higher is better. Chimera is limited by monitor refresh, otherwise it would have even higher performance.

\subsubsection{Scalability}

Even if Chimera is mainly thought for being used on computers or tablets, to stress test the scalability are used two smartphones: a Samsung Galaxy A70 2019 and a very old Samsumg A5 2015.

On Galaxy A70, if the memory is cleared, it is possible to load the model, that other software have difficulty to manage on the $\mathrm{PC}$, without any problems and it is very fluid.

On the five-year old A5, it is no possible to load it at fully quality, due to the small RAM available: Chimera offers yet the

\footnotetext{
${ }^{4}$ The FPS is the way to measure performances in the computer graphic area; it is important both the stability of the FPS and its value: a value of 60 FPS is perfect, between 30 and 60 FPS is still acceptable for the fruition, but a good eye sees less fluidity; when the FPS drops down 30 FPS every people detects poor fluidity, stuttering, motion sickness and so on; under 15-20 FPS the video turns into a series of jerky images.
} 
possibility to load the $3 \mathrm{~d}$ choosing between 7 different lower Levels of Details ${ }^{5}$, independently for the mesh and the textures; the lower LoD are automatically computed during the import of the model. Using textures at LoD2 (25 textures of reduced size of $1.024 \times 1.024$ pixel each, for a total of 26,21Mpixel, and model at LoD4 (0.4 of percentage reduction), it is possible to load the models even on this old smartphone; considering the small dimension of the screen, the loss in quality is not visible until high level of zoom.

\section{CASES OF STUDY}

Although Chimera is currently used in many projects of $3 \mathrm{D}$ Survey Group of Politecnico di Milano and also tested in Università degli Studi in Parma, two different cases of study are chosen to show the capability to cover different contests.

\subsection{Umm al-Dabadib}

The first case regards the project L.I.F.E, funded by the European Research Council (ERC) under the European Union's Horizon 2020 (Rossi et al, Springer, 2020).

The general scope of L.I.F.E. is to offer a complete set of archaeological and environmental data to be used to investigate Late Roman settlements along frontier desert areas and to reconstruct the underlying strategy to control the empire's desert edges. The specific case study is the Late Roman archaeological site of Umm al-Dabadib, located at the outskirts of the the Kharga Oasis (Egypt's Western Desert), that in the Fourth Century AD represented a portion of the southern boundary of the empire.

Differently from the sites located closer to the inhabited portion of the oasis, Umm al-Dabadib still contains the virtually intact remains of both an imposing settlement and its contemporary, vast and elaborated agricultural system.

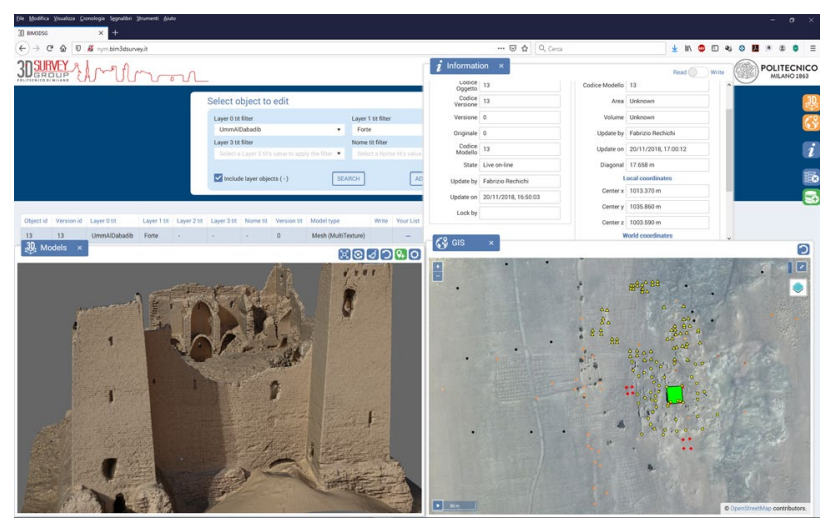

Figure 9 - Chimera's system for Umm al-Dabadib; it is shown the Fort, a detail of the GIS area, through satellite images, and information component.

Another key aspect is the data sharing and the dissemination. Chimera is fundamental for the projects because can cover all the requirements of this case. In fact, the main need is the capability to manage objects at different scale:

a) The territorial one, for the mapping of the agricultural system, the aqueduct and the position of the settlement and of the finds.

5 It is important not to confuse "graphic" LoD, used in this context and that define the quality from the original to the more decimated, and the LoD nowdays used in $\mathrm{CH}$ to define the descriptive the level of described details. b) Buildings one, for the settlement, the Fort and other small buildings.

c) Single and small objects, for all the finds.

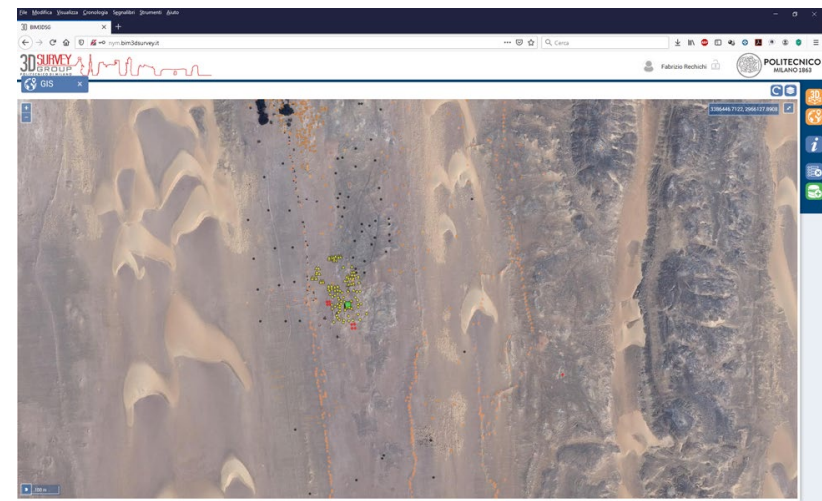

Figure 10 - The GIS component working on the Umm alDabadib area, with the use of satellite images.

The system also helps specialist to cooperate in real time from different sites.

The $3 \mathrm{~d}$ component supports very high resolution models that can preserve the remains for the future; the hotspot system lets to insert the finds for which it would be a waste of time to make a model, such as seeds and all others small objects that not have an aesthetic importance.

Another important feature is the textual components that lets to track also that object for which there is no interest to have a $3 \mathrm{~d}$ model or to precise georeference with a hotspot, but that must be however recorded and registered.

Finally, the system will be used for the dissemination of all the data collected during the survey and subsequent studies.

\subsection{Sacri Monti}

A "Sacro Monte" is a devotional path, in an isolated and beautiful landscape; it is composed by chapels and churches that contain inside artistic scenes that evoke the theme described. The first was built in 1480 in Varallo, Piedmont. During the 17$18^{\text {th }}$ others succeed at Crea, Orta, Varese, Oropa, Ossuccio, Ghiffa, Domodossola, and Valperga. In 2003 UNESCO registered the site "Sacri Monti of Piedmont and Lombardy" in its World Heritage List.

The main need of "Sacri Monti" Circuit is to find a method to manage the ordinary and extraordinary maintenance activities of the site, which involve cleaning, substitution, decay analyses, interventions, and more. In these activities, many people with different competencies, skills, and education must cooperate.

There is the necessity to have a unique platform where to collect all data about interventions, analyses and information, both to facilitate their exchange among different actors and to track them for the future. This is also fundamental for the UNESCO Periodic Reporting, that the "Ente di Gestione dei Sacri Monti" must produce (Achille et al., 2019).

Chimera it is used to respond to the previous described necessity. The key feature for this case of study is the support of the SubVersion because it lets to track the status and the changes through time, without the need to make new models for the new situation. Another important feature is the capability to easily and quickly configure an ad-hoc information system; the first phase of the work is to define which information the Ente needs for each object categories, to set up Chimera for its specific needs.

For this case of study, it is not necessary to have very high quality reality based $3 \mathrm{~d}$ models, thus some simplified BIM 
models are made, both global and also divided into the single parts, such as roofs, columns, walls, and so on.

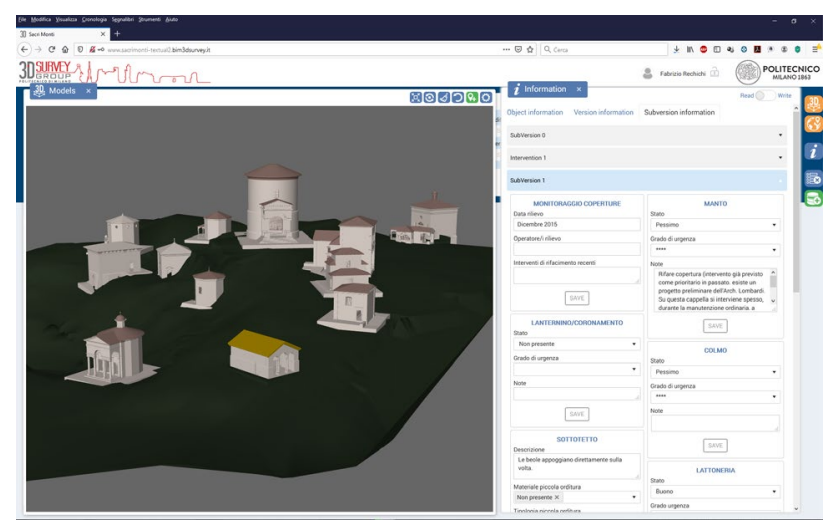

Figure 11 - Chimera working with Sacro Monte of Varallo; it is displayed the SubVersion information of a roof, that tracking the status of that roof through time.

Selecting each object, it is possible to see both the actual state and all its history, previous states and intervention. It is also possible to open a new intervention to add a new state and tracking the activities and or the current degradation.

The best result in this case of study is that the Ente is currently using Chimera in the daily work, as an important support and help to their activities.

\section{CONCLUSION}

All the tests performed on Chimera and its use in the daily work, showed that Chimera can effectively respond to the needs of a variety of activities within the realm of Cultural Heritage. Its capability to quickly set up a custom information system, modifiable at any time, is fundamental to cover every different case of study.

The capability to concurrently work at different scales, from a "single object level", to the a "building level", to a more extensive "environmental level" is not only fundamental because of its flexibility, but also because it allows the adoption of a more complete prospective, by managing transversal information and analysing each case from different points of views and at different levels of detail.

The structure of Chimera also allows to easily add any needed functionality, both in the BIM and the GIS components, that it has not yet been developed; some of them have been already planned, after the completion of all functions in the new UI, whilst others may be added at a later stage, thus following the evolution of the external requests.

\section{ACKNOWLEDGEMENTS}

This article is the result of the research carried out by the project L.I.F.E., funded by the European Research Council (ERC) under the European Union's Horizon 2020 research and innovation programme (grant agreement No. 681673), directed by C. Rossi and carried out at Politecnico di Milano.

The work here presented is part of the research activities on "Informative systems at support of Cultural Heritage maintenance" conducted since years by 3DSurvey Group and it is the result of the proficient collaboration with the University of Parma. A great thanks to Prof.ssa Cristiana Achille e Prof.
Francesco Fassi and Prof. Riccardo Roncella for their support and scientific contribution.

\section{REFERENCES}

Achille, C., Tommasi, C., Rechichi, F., Fassi, F., and De Filippis, E., 2019: Towards an advanced conservation strategy: a structured database for sharing $3 \mathrm{~d}$ documentation between expert users, Int. Arch. Photogramm. Remote Sens. Spatial Inf. Sci., XLII-2/W15, 9-16, https://doi.org/10.5194/isprs-archivesXLII-2-W15-9-2019.

Achille, C., Fassi, F., Mandelli, A., Perfetti, L., Rechichi, F., Teruggi, S., 2020: From a Traditional to a Digital Site: 20082019. The History of Milan Cathedral Surveys. In: Daniotti B., Gianinetto M., Della Torre S. (eds) Digital Transformation of the Design, Construction and Management Processes of the Built Environment. Research for Development. Springer, Cham, https://doi.org/10.1007/978-3-030-33570-0_30.

Agustín, L., Quintilla, M., 2019: Virtual reconstruction in BIM technology and digital inventories of heritage, Int. Arch. Photogramm. Remote Sens. Spatial Inf. Sci., XLII-2/W15, 2531, https://doi.org/10.5194/isprs-archives-XLII-2-W15-252019.

Amirebrahimi, S., Rajabifard, A., Mendis, P., Ngo, T., 2016: A BIM-GIS integration method in support of the assessment and 3D visualisation of flood damage to a building, Journal of Spatial Science, https://doi.org/10.1080/14498596.2016.1189365.

Arroyo Ohori, K., Biljecki, F., Diakité, A., Krijnen, T., Ledoux, H., and Stoter, J., 2017: Towards an integration of GIS and BIM data: what are the geometric and topological issues?, ISPRS Ann. Photogramm. Remote Sens. Spatial Inf. Sci., IV-4/W5, 18, https://doi.org/10.5194/isprs-annals-IV-4-W5-1-2017.

Autodesk, ESRI, 2019: https://www.autodesk.com/solutions/bim/hub/autodesk-esri and https://www.autodesk.com/campaigns/bim-gis (Last accessed on May 2020).

Baik, A., Yaagoubi, R., Boehm, J., 2015: Integration of Jeddah Historical BIM and 3D GIS for Documentation and Restoration of Historical Monument, Int. Arch. Photogramm. Remote Sens. Spatial Inf. Sci., XL-5/W7, 29-34, https://doi.org/10.5194/isprsarchives-XL-5-W7-29-2015.

Barazzetti, L., Banfi, F., 2017: BIM and GIS: when parametric modeling meets geospatial data, ISPRS Ann. Photogramm. Remote Sens. Spatial Inf. Sci., IV-5/W1, 1-8, https://doi.org/10.5194/isprs-annals-IV-5-W1-1-2017.

Bruno, N., Roncella, R., 2019: HBIM for conservation: A new proposal for information modeling. Remote Sensing, 11(15), 1751, https://doi.org/10.3390/rs11151751.

Carvajal-Ramírez, F., Martínez-Carridondo, P., Yero-Paneque, L., and Agüera-Vega, F., 2019: UAV photogrammetry and HBIM for the virtual reconstruction of heritage, Int. Arch. Photogramm. Remote Sens. Spatial Inf. Sci., XLII-2/W15, 271278, https://doi.org/10.5194/isprs-archives-XLII-2-W15-2712019 . 
CityGML, http://www.citygml.org (Last accessed on May 2020).

D'Andrea, A., Di Lillo, A., Laino, A., Pesaresi, P. M., 2019: Documenting large archaeological sites, managing data, planning conservation and maintenance: the Herculaneum conservation project experience, Int. Arch. Photogramm. Remote Sens. Spatial Inf. Sci., XLII-2/W15, 359-364, https://doi.org/10.5194/isprs-archives-XLII-2-W15-359-2019.

Del Curto, D., Garzulino, A., Allegretti, F., Mazza, S., 2019: GIS or BIM? A comparison applied to the conservation management plan of a 20th century architectural heritage, Int. Arch. Photogramm. Remote Sens. Spatial Inf. Sci., XLII-2/W15, 365-372, https://doi.org/10.5194/isprs-archives-XLII-2-W15$365-2019$.

Di Stefano, F., Malinverni, E. S., Pierdicca, R., Fangi, G., and Ejupi, S., 2019: HBIM implementation for an ottoman mosque. Case of study: sultan Mehmet Fatih II mosque in Kosovo, Int. Arch. Photogramm. Remote Sens. Spatial Inf. Sci., XLII-2/W15, 429-436, https://doi.org/10.5194/isprs-archives-XLII-2-W15429-2019.

Dore, C., Murphy, M., 2012: Integration of historic building information modelling (HBIM) and 3D GIS for recording and managing cultural heritage sites. In Virtual Systems in the Information Society, Proceedings of the 18th International Conference on Virtual Systems and Multimedia (VSMM), 369 (376), https://doi.org/10.1109/VSMM.2012.6365947.

Fai, S., Graham, K., Duckworth, T., Wood, N., Attar, R., 2011: Building information modelling and heritage documentation, Conference Proceedings of XXIII CIPA International Symposium, 8.

Fassi, F., Achille, C., Mandelli, A., Rechichi, F., Parri, S., 2015: A new idea of BIM system for visualization, web sharing and using huge complex $3 \mathrm{~d}$ models for facility management, Int. Arch. Photogramm. Remote Sens. Spatial Inf. Sci., XL-5/W4, 359-366, https://doi.org/10.5194/isprsarchives-XL-5-W4-3592015.

Fassi, F., Fregonese, L., Adami, A., Rechichi, F., 2017: BIM system for the conservation and preservation of the mosaics of San Marco in Venice, Int. Arch. Photogramm. Remote Sens. Spatial Inf. Sci., XLII-2/W5, 229-236, https://doi.org/10.5194/isprs-archives-XLII-2-W5-229-2017.

Gilbert, T., Barr, S., James, P., Morley, J., Ji, Q., 2018: Software Systems Approach to Multi-Scale GIS-BIM Utility Infrastructure Network Integration and Resource Flow Simulation, International Journal of Geo-Information 7(8):310, https://doi.org/10.3390/ijgi7080310.

GeoServer, http://geoserver.org (Last accessed on May 2020).

Liu, X., Wang, X., Wright, G., Cheng, J.C.P., Li, X., Liu, R., 2017: A State-of-the-Art Review on the Integration of Building Information Modeling (BIM) and Geographic Information System (GIS). ISPRS Int. J. Geo-Inf., $6 \quad$ (2), https://doi.org/10.3390/ijgi6020053.

Ma, Z., Ren, Y., 2017: Integrated Application of BIM and GIS: An Overview, Creative Construction Conference 2017, CCC 2017, https://doi.org/10.1016/j.proeng.2017.08.064.
Matrone, F., Colucci, E., De Ruvo, V., Lingua, A., and Spanò, A., 2019: HBIM in a semantic 3d GIS database, Int. Arch. Photogramm. Remote Sens. Spatial Inf. Sci., XLII-2/W11, 857865, https://doi.org/10.5194/isprs-archives-XLII-2-W11-8572019 .

Ohori, K. A., Diakité, A., Krijnen, T., Ledoux, H., Stoter, J., 2018: Processing BIM and GIS Models in Practice: Experiences and Recommendations from a GeoBIM Project in The Netherlands, International Journal of Geo-Information 7(8):311, https://doi.org/10.3390/ijgi7080311.

Open Geospatial Consortium, https://www.ogc.org/standards/sld (Last accessed on May 2020).

OpenLayers, online at https://openlayers.org (Last accessed on May 2020).

PostGIS, https://postgis.net (Last accessed on May 2020).

PostgreSQL, https://www.postgresql.org (Last accessed on May 2020).

Rechichi, F., Mandelli, A., Achille, C., and Fassi, F., 2016: Sharing high-resolution models and information on web: the web module of BIM3DSG system, Int. Arch. Photogramm. Remote Sens. Spatial Inf. Sci., XLI-B5, 703-710, https://doi.org/10.5194/isprs-archives-XLI-B5-703-2016.

Rechichi, F., Fiorillo, F., 2019: Creating, visualizing and sharing high-poly and multi-textures models on the web, Int. Arch. Photogramm. Remote Sens. Spatial Inf. Sci., XLII-2/W9, 655-662, https://doi.org/10.5194/isprs-archives-XLII-2-W9$655-2019$

Rechichi, F., 2020, ITinnovations Library, online at https://www.itinnovations.it (Last accessed on May 2020).

Rossi C., Achille C., Fassi F., Lori F., Rechichi F., Fiorillo F., 2020: Digital Workflow to Support Archaeological Excavation: From the 3D Survey to the Websharing of Data. In: Aste N., Della Torre S., Talamo C., Adhikari R., Rossi C. (eds) Innovative Models for Sustainable Development in Emerging African Countries. Research for Development., Springer, Cham, https://doi.org/10.1007/978-3-030-33323-2_13.

Telerik, 2020, KendoUI, online at https://www.telerik.com/kendo-ui (Last accessed on May 2020).

Tommasi, C., Fiorillo, F., Jiménez Fernández-Palacios, B., and Achille, C., 2019: Access and web-sharing of 3d digital documentation of environmental and architectural heritage, Int. Arch. Photogramm. Remote Sens. Spatial Inf. Sci., XLII-2/W9, 707-714, https://doi.org/10.5194/isprs-archives-XLII-2-W9707-2019.

W3C, Web Persistent Storage, 2018, online at http://www.w3.org/TR/webstorage (Last accessed on May 2020).

xeoLabs, SceneJS, online at http://scenejs.org (Last accessed on May 2020). 